\title{
Statistical analysis plan for the BLING III study: a phase 3 multicentre randomised controlled trial of continuous versus intermittent $\beta$-lactam antibiotic infusion in critically ill patients with sepsis
}

Laurent Billot, Jeffrey Lipman, Stephen J Brett, Jan J De Waele, Menino Osbert Cotta, Joshua S Davis, Simon Finfer, Naomi Hammond, Serena Knowles, Shay McGuinness, John Myburgh, David L Paterson, Sandra Peake, Dorrilyn Rajbhandari, Andrew Rhodes, Jason A Roberts, Claire Roger, Charudatt Shirwadkar, Therese Starr, Colman Taylor and Joel M Dulhunty; for the BLING III Investigators

The aim of the $\beta$-Lactam Infusion Group (BLING) III study is to determine whether continuous infusion of a $\beta$-lactam antibiotic (piperacillin-tazobactam or meropenem) results in decreased all-cause day 90 mortality compared with intermittent $\beta$-lactam antibiotic infusion in 7000 critically ill patients with sepsis. The study protocol has been previously published. ${ }^{1}$ This article describes the pre-specified statistical analysis plan finalised by the trial statistician (LB) and chief investigators and approved by the BLING III management committee before the completion of patient enrolment and database lock.

\section{Study design}

The BLING III study is a prospective, multicentre, open label, phase 3, randomised controlled trial that is being conducted in 95 intensive care units (ICUs) in Australia, Belgium, France, Malaysia, New Zealand, the United Kingdom and Sweden. Eligible patients who are treated with either piperacillintazobactam or meropenem for a documented infection or strong suspicion of infection are randomly assigned to receive the $\beta$-lactam antibiotic by either intermittent or continuous infusion in the ICU up to a maximum of 14 days. Dose and selection of the $\beta$-lactam antibiotic is at clinician discretion and independent of group allocation. Day 1 is defined as the date of randomisation. Primary, secondary and tertiary outcomes are described in Table 1.

\section{Participants}

Patients in the ICU being treated with either piperacillintazobactam or meropenem for a documented infection or strong suspicion of infection, who are expected to stay in the ICU beyond the following calendar day and who meet one or more organ dysfunction criteria will be eligible for enrolment. Inclusion and exclusion criteria are summarised

\begin{abstract}
Background: The $\beta$-Lactam Infusion Group (BLING) III study is a prospective, multicentre, open, phase 3 randomised controlled trial comparing continuous infusion with intermittent infusion of $\beta$-lactam antibiotics in 7000 critically ill patients with sepsis.
\end{abstract}

Objective: To describe a statistical analysis plan for the BLING III study.

Methods: The statistical analysis plan was designed by the trial statistician and chief investigators and approved by the BLING III management committee before the completion of data collection. Statistical analyses for primary, secondary and tertiary outcomes and planned subgroup analyses are described in detail. Interim analysis by the Data Safety and Monitoring Committee (DSMC) has been conducted in accordance with a pre-specified DSMC charter.

Results and conclusions: The statistical analysis plan for the BLING III study is published before completion of data collection and unblinding to minimise analysis bias and facilitate public access and transparent analysis and reporting of study findings.

Trial registration: ClinicalTrials.gov Registry NCT03212990.

Crit Care Resusc 2021; 23 (3): 273-84

in Table 2. Participants are randomised using a minimisation algorithm with stratification by site via a passwordprotected, secure web-based interface.

\section{Sample size}

A sample size of 6558 (3279 per group) is required to provide $90 \%$ power to detect an absolute risk reduction 


\section{Table 1. Primary, secondary and tertiary study outcomes}

Primary outcome:

- All-cause mortality within 90 days after randomisation

Secondary outcomes:

- Clinical cure at day 14 after randomisation*

- New acquisition, colonisation or infection with a multiresistant organism or Clostridium difficile diarrhoea up to 14 days after randomisation

- All-cause ICU mortality

- All-cause hospital mortality

Tertiary outcomes:

- ICU length of stay

- Hospital length of stay

- Duration of mechanical ventilation in ICU up to 90 days after randomisation

- Duration of renal replacement therapy up to 90 days after randomisation

ICU $=$ intensive care unit. * Clinical cure is defined as the completion of the $\beta$-lactam antibiotic treatment course on or before day 14 without recommencement of antibiotic therapy within 48 hours of cessation for the same infectious episode.

Table 2. Inclusion and exclusion criteria for the $\beta$-Lactam Infusion Group (BLING) III study

Inclusion criteria:

- The patient has a documented site of infection or strong suspicion of infection

- The patient is expected to be in the ICU the day after tomorrow

- The patient has been commenced on piperacillin-tazobactam or meropenem to treat the episode of infection

- Giving piperacillin-tazobactam or meropenem by intermittent infusion or continuous infusion is considered equally appropriate for the patient

- One or more organ dysfunction criteria in the previous 24 hours:

- MAP $<60 \mathrm{mmHg}$ for at least 1 hour

- vasopressors required for $>4$ hours

- respiratory support using supplemental high flow nasal prongs, continuous positive airway pressure, bilevel positive airway pressure or invasive mechanical ventilation for at least 1 hour

- serum creatinine concentration $>220 \mu \mathrm{mol} / \mathrm{L}$ or $<2.49 \mathrm{mg} / \mathrm{dL}$

Exclusion criteria:

- The patient is aged $<18$ years

- The patient has received piperacillin-tazobactam or meropenem for more than 24 hours during current infectious episode

- The patient is known or suspected to be pregnant

- The patient has a known allergy to piperacillin-tazobactam, meropenem or penicillin

- The patient is requiring renal replacement therapy at the time of randomisation, including renal replacement therapy for chronic renal failure

- The attending physician or patient or surrogate legal decision maker is not committed to advanced life support, including mechanical ventilation, dialysis and vasopressor administration, for at least the next 48 hours

- The patient's death is deemed imminent and inevitable

- The patient has previously been enrolled in BLING III

$\mathrm{ICU}=$ intensive care unit; $\mathrm{MAP}=$ mean arterial pressure. of $3.5 \%$ in 90 -day mortality in the continuous infusion group from baseline mortality of $27.5 \%$ with $\alpha=0.05 .^{1,2}$ After adjusting for up to $5 \%$ of patients lost to follow-up (345) and rounding up, the target sample size is 7000 (3500 per group).

\section{Interim analysis}

One interim analysis occurred when 3500 patients $(50 \%$ of planned recruitment) had completed the 90-day followup. An independent Data Safety Monitoring Committee (DSMC) is responsible for the safety assessment of the trial during its conduct, including the interim analysis. The DSMC charter is available in the Online Appendix.

\section{Multiplicity adjustments}

All tests are to be two-sided with a nominal level of $\alpha$ set at $5 \%$. Analyses of the primary outcome (all-cause mortality at 90 days) will be unadjusted for multiplicity; however, the family-wise error rate will be controlled across secondary outcomes (one family) and tertiary outcomes (one family) using a HolmBonferroni correction. ${ }^{3}$ No other multiplicity adjustment will be applied.

\section{Datasets analysed}

Analyses will be conducted on an intention to treat (ITT) analysis dataset. The ITT dataset will include all randomised study participants regardless of their compliance with the rules of the study and excluding data for which consent is either not obtained, data are not approved for 


\section{ORIGINAL ARTICLE}

use by the relevant human research ethics committee or institutional review board, or where consent is withdrawn. The ITT dataset will be used for the analyses of all primary, secondary and tertiary outcomes. All safety-related analyses will be based on a per protocol analysis of participants who received one or more doses of the $\beta$-lactam antibiotic in the assigned treatment group. Participants who did not receive at least one dose of assigned treatment will be excluded from the safety analysis.

The flow of patients through the trial will be displayed in a CONSORT (Consolidated Standards of Reporting Trials) diagram (Figure 1). ${ }^{4}$ The report will include the number of screened patients who met the study inclusion criteria, the number of patients who were included and reasons for exclusion of non-included patients.

\section{Data validation}

The study database is maintained at the George Institute for Global Health. All data queries and corrections will be conducted by the George Institute for Global Health in a blinded manner and before database lock. Data received by the George Institute for Global Health statistician will be examined for missing values and outliers. Measures of central tendency and dispersion for continuous study parameters will be portrayed along with box and whisker plots. Extreme or unexpected values will be examined individually for authenticity and data discrepancies addressed where appropriate. Additional audit and statistical checks will be performed as necessary.

\section{Patient characteristics and baseline comparisons}

Description of the baseline characteristics will be presented by treatment group. Discrete variables will be summarised by frequencies and percentages. Percentages will be calculated according to the number of patients for whom data are available. Continuous variables will be summarised using mean and standard deviation (SD) and median and interquartile range (IQR). Baseline measures for all patients will be presented as shown in Table 3, Table 4, Table 5 and Table 6.

\section{Figure 1. CONSORT (Consolidated Standards of Reporting Trials) flow diagram}

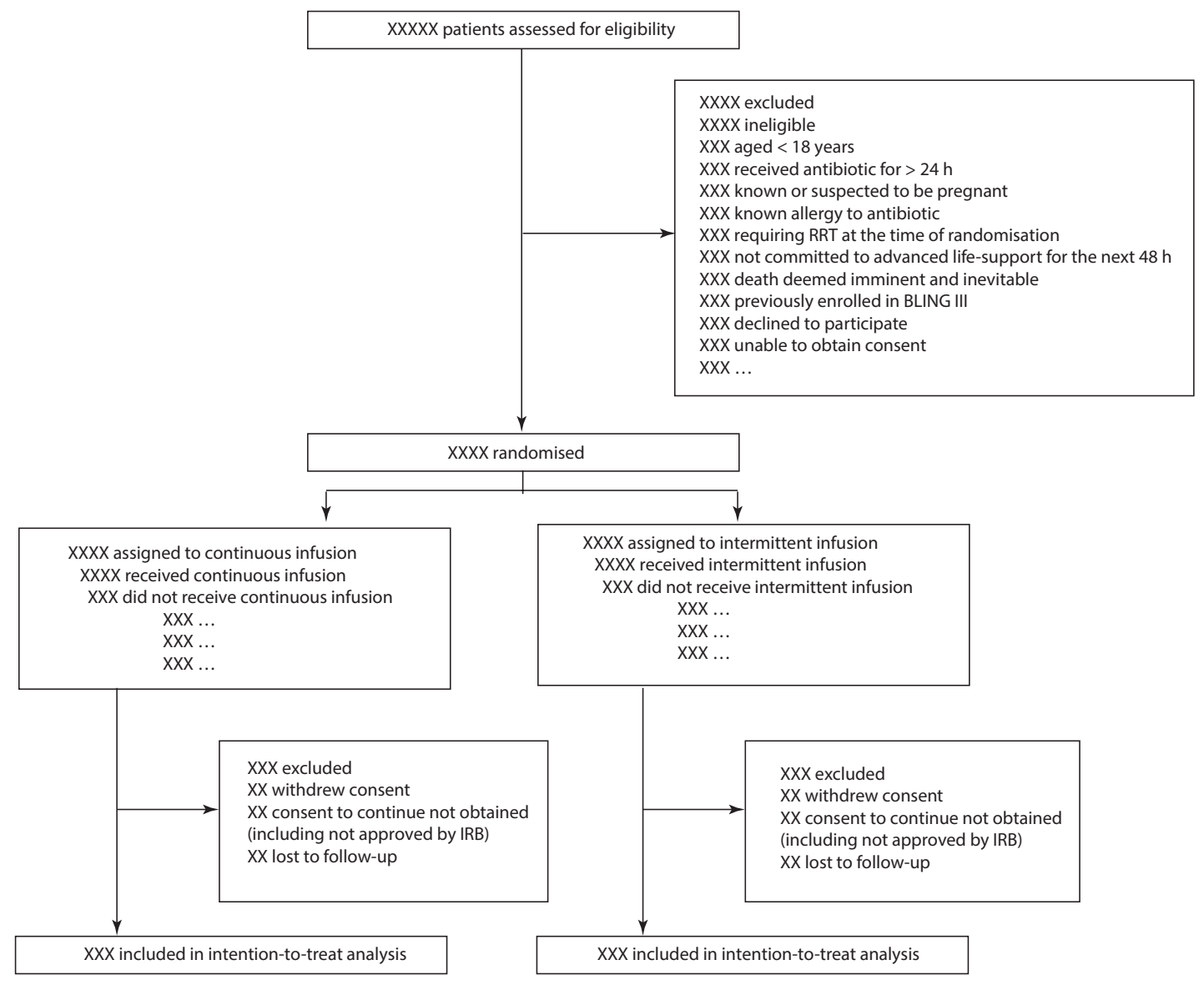

IRB = institutional review board; RRT = renal replacement therapy. 


\section{Table 3. Baseline characteristics}

\begin{tabular}{|c|c|c|}
\hline Characteristic & $\begin{array}{l}\text { Continuous } \\
\text { infusion } \\
(n=X X X X)\end{array}$ & $\begin{array}{l}\text { Intermittent } \\
\text { infusion } \\
(n=\mathrm{XXXX)}\end{array}$ \\
\hline Age, years & $\begin{array}{c}\text { Mean (SD)/median } \\
\text { (IQR) }\end{array}$ & $\begin{array}{c}\text { Mean (SD)/median } \\
\text { (IQR) }\end{array}$ \\
\hline Sex, female & $n(\%)$ & $n(\%)$ \\
\hline Weight, kg & $\begin{array}{c}\text { Mean (SD)/median } \\
\text { (IQR) }\end{array}$ & $\begin{array}{c}\text { Mean (SD)/median } \\
\text { (IQR) }\end{array}$ \\
\hline Height, $\mathrm{cm}$ & $\begin{array}{c}\text { Mean (SD)/median } \\
\text { (IQR) }\end{array}$ & $\begin{array}{c}\text { Mean (SD)/median } \\
\text { (IQR) }\end{array}$ \\
\hline \multicolumn{3}{|l|}{ Source of ICU admission } \\
\hline $\begin{array}{l}\text { Accident and emergency } \\
\text { department }\end{array}$ & $n(\%)$ & $n(\%)$ \\
\hline Hospital floor (ie, wards) & $n(\%)$ & $n(\%)$ \\
\hline Transfer from another ICU & $n(\%)$ & $n(\%)$ \\
\hline Transfer from another hospital & $n(\%)$ & $n(\%)$ \\
\hline $\begin{array}{l}\text { From OT following emergency } \\
\text { surgery }\end{array}$ & $n(\%)$ & $n(\%)$ \\
\hline $\begin{array}{l}\text { From OT following elective } \\
\text { surgery }\end{array}$ & $n(\%)$ & $n(\%)$ \\
\hline Time since ICU admission, hours & $\begin{array}{c}\text { Mean (SD)/median } \\
\text { (IQR) }\end{array}$ & $\begin{array}{c}\text { Mean (SD)/median } \\
\text { (IQR) }\end{array}$ \\
\hline APACHE III score & $\begin{array}{c}\text { Mean (SD)/median } \\
\text { (IQR) }\end{array}$ & $\begin{array}{c}\text { Mean (SD)/median } \\
\text { (IQR) }\end{array}$ \\
\hline $\begin{array}{l}\text { Lowest } \mathrm{PaO}_{2}: \mathrm{FiO}_{2} \text { ratio in the } 24 \\
\text { hours before randomisation }\end{array}$ & $\begin{array}{c}\text { Mean (SD)/median } \\
(\mathrm{IQR})\end{array}$ & $\begin{array}{c}\text { Mean (SD)/median } \\
\text { (IQR) }\end{array}$ \\
\hline Highest creatinine, $\mu \mathrm{mol} / \mathrm{L}$ & $\begin{array}{c}\text { Mean (SD)/median } \\
(\mathrm{IQR})\end{array}$ & $\begin{array}{c}\text { Mean (SD)/median } \\
\text { (IQR) }\end{array}$ \\
\hline Highest bilirubin, $\mu \mathrm{mol} / \mathrm{L}$ & $\begin{array}{c}\text { Mean (SD)/median } \\
(\mathrm{IQR})\end{array}$ & $\begin{array}{c}\text { Mean (SD)/median } \\
\text { (IQR) }\end{array}$ \\
\hline Lowest platelet count, $\times 10^{9} / \mathrm{L}$ & $\begin{array}{c}\text { Mean (SD)/median } \\
\text { (IQR) }\end{array}$ & $\begin{array}{c}\text { Mean (SD)/median } \\
\text { (IQR) }\end{array}$ \\
\hline $\begin{array}{l}\text { Lowest MAP in } 24 \text { hours before } \\
\text { randomisation, } \mathrm{mmHg}\end{array}$ & $\begin{array}{c}\text { Mean (SD)/median } \\
\text { (IQR) }\end{array}$ & $\begin{array}{c}\text { Mean (SD)/median } \\
\text { (IQR) }\end{array}$ \\
\hline $\begin{array}{l}\text { Worst Glasgow Coma Score, non- } \\
\text { sedated }\end{array}$ & $\begin{array}{c}\text { Mean (SD)/median } \\
\text { (IQR) }\end{array}$ & $\begin{array}{c}\text { Mean (SD)/median } \\
\text { (IQR) }\end{array}$ \\
\hline $\begin{array}{l}\text { Receiving inotropes or vasopressors } \\
\text { in the } 24 \text { hours before } \\
\text { randomisation }\end{array}$ & $n(\%)$ & $n(\%)$ \\
\hline $\begin{array}{l}\text { Receiving antibiotics in the } 24 \\
\text { hours before randomisation* }\end{array}$ & $n(\%)$ & $n(\%)$ \\
\hline
\end{tabular}

APACHE $=$ Acute Physiology and Chronic Health Evaluation; $\mathrm{FiO}_{2}=$ fraction of inspired oxygen ICU = intensive care unit; IQR = interquartile range; $\mathrm{MAP}=$ mean arterial pressure; $\mathrm{OT}=$ operating theatre; $\mathrm{PaO}_{2}=$ arterial partial pressure of oxygen $\mathrm{SD}=$ standard deviation . * Other than piperacillin-tazobactam or meropenem. report the number and proportion of patients receiving $\beta$-lactam antibiotics as well as the dose administered summarised as the mean (SD) and median (IQR) (Table 7). This will be done by treatment group and separately for piperacillin-tazobactam and meropenem. Assigned treatment will be summarised using the following variables: i) time on $\beta$-lactam antibiotic treatment defined as the number of days between the first and last day of piperacillin-tazobactam and/or meropenem administration (up to day 16), and ii) cumulative dose of $\beta$-lactam antibiotic (piperacillintazobactam and/or meropenem) received ( $\mathrm{mg}$ ) up to day 16. Time on study treatment and cumulative dose will be summarised using mean (SD) and median (IQR), with differences between treatment groups tested using a linear model with a random site effect. Other administered antibiotics (regardless of route) will be reported as the number and percentage of patients receiving at least one dose in the 24 hours before randomisation up to day 16 . Protocol deviations will be summarised as the number of deviations by type. All protocol deviations will be listed together with a description of the deviation.

\section{Analysis of the primary efficacy endpoint}

The primary aim of this study is to compare the effect of continuous versus intermittent infusion of piperacillin-tazobactam or meropenem on all-cause mortality up to day 90 .

\section{Main analysis}

The primary endpoint is the proportion of patients who have died up to and including day 90 after randomisation. To account for stratification by site and to maximise power, ${ }^{5}$ the main analysis will be performed using logistic regression, with treatment allocation as a fixed effect and site as a random effect. ${ }^{6}$ The effect of the intervention will be presented as the odds ratio (OR) of death and its $95 \%$ confidence interval $(\mathrm{Cl})$. Crude proportions by treatment arm will also be reported with an unadjusted OR and $95 \% \mathrm{Cl}$ and a $\chi^{2}$ test $P$ value (Table 8 ). For ease of interpretation, risk difference and $95 \% \mathrm{Cl}$ will also be presented. The adjusted OR and $95 \% \mathrm{Cl}$ will be converted to an adjusted risk difference and $95 \% \mathrm{Cl}$ using the Hummel and Wiseman method described by Reeve. ${ }^{7}$

\section{Treatments and protocol deviations}

For each day between day 1 and day 16 , noting randomised treatment continues to a maximum of 14 days, we will 


\begin{tabular}{|c|c|c|}
\hline \multirow{2}{*}{$\begin{array}{l}\text { Table 4. Acute Physiology and } \\
\text { (APACHE) III diagnosis } \\
\text { Diagnosis }\end{array}$} & \multirow{2}{*}{$\begin{array}{l}\text { Chronic Hea } \\
\text { Continuous } \\
\text { infusion } \\
(n=X X X X)\end{array}$} & \multirow{2}{*}{$\begin{array}{l}\text { Evaluatio } \\
\text { Intermittent } \\
\text { infusion } \\
(n=X X X X)\end{array}$} \\
\hline & & \\
\hline \multicolumn{3}{|l|}{ Non-operative diagnoses } \\
\hline Cardiovascular & $n(\%)$ & $n(\%)$ \\
\hline Respiratory & $n(\%)$ & $n(\%)$ \\
\hline Gastrointestinal & $n(\%)$ & $n(\%)$ \\
\hline Neurological & $n(\%)$ & $n(\%)$ \\
\hline Sepsis & $n(\%)$ & $n(\%)$ \\
\hline Trauma & $n(\%)$ & $n(\%)$ \\
\hline Metabolic & $n(\%)$ & $n(\%)$ \\
\hline Haematological & $n(\%)$ & $n(\%)$ \\
\hline Renal/genitourinary & $n(\%)$ & $n(\%)$ \\
\hline Musculoskeletal/skin & $n(\%)$ & $n(\%)$ \\
\hline \multicolumn{3}{|l|}{ Other } \\
\hline \multicolumn{3}{|l|}{ Operative diagnoses } \\
\hline Cardiovascular & $n(\%)$ & $n(\%)$ \\
\hline Respiratory & $n(\%)$ & $n(\%)$ \\
\hline Gastrointestinal & $n(\%)$ & $n(\%)$ \\
\hline Neurological & $n(\%)$ & $n(\%)$ \\
\hline Trauma & $n(\%)$ & $n(\%)$ \\
\hline Metabolic & $n(\%)$ & $n(\%)$ \\
\hline Haematological & $n(\%)$ & $n(\%)$ \\
\hline Renal/genitourinary & $n(\%)$ & $n(\%)$ \\
\hline Gynaecological & $n(\%)$ & $n(\%)$ \\
\hline Musculoskeletal/skin & $n(\%)$ & $n(\%)$ \\
\hline
\end{tabular}

\begin{tabular}{lcc} 
Table 5. Primary site of infection & & \\
Primary site of infection & $\begin{array}{c}\text { Continuous } \\
\text { infusion } \\
(\boldsymbol{n}=\mathbf{X X X X )}\end{array}$ & $\begin{array}{c}\text { Intermittent } \\
\text { infusion } \\
(\boldsymbol{n}=\mathbf{X X X X )}\end{array}$ \\
\hline Pulmonary & $n(\%)$ & $n(\%)$ \\
Intra-abdominal & $n(\%)$ & $n(\%)$ \\
Blood & $n(\%)$ & $n(\%)$ \\
Skin & $n(\%)$ & $n(\%)$ \\
Urinary & $n(\%)$ & $n(\%)$ \\
Intravenous catheter & $n(\%)$ & $n(\%)$ \\
Central nervous system & $n(\%)$ & $n(\%)$ \\
Gut & $n(\%)$ & $n(\%)$ \\
Endocarditis & $n(\%)$ & $n(\%)$ \\
Other & $n(\%)$ & $n(\%)$ \\
\hline
\end{tabular}

\section{Adjusted analyses}

Adjusted analyses will be performed by adding the following covariates to the main logistic regression model: sex, Acute Physiology and Chronic Health Evaluation (APACHE) III score at randomisation (as a continuous variable), source of admission (admitted from the operating theatre following emergency or elective surgery $v$ other) and type of $\beta$-lactam antibiotic administered (piperacillin-tazobactam or meropenem). The adjusted treatment effect will be reported as the adjusted OR and $95 \% \mathrm{Cl}$. If more than $3 \%$ of observations are lost after adding covariates, multiple imputations will be used as described in the "Treatment of missing data" section.

\section{Subgroup analyses}

Five pre-specified subgroup analyses will be carried out irrespective of whether there is a significant treatment effect on the primary outcome. Subgroups are defined as follows:

- presence versus absence of pulmonary infection at baseline;

- type of $\beta$-lactam antibiotic administered (piperacillintazobactam or meropenem);

- age (< 65 years $v \geq 65$ years);

- sex (male $v$ female); and

- low versus high severity of illness (defined by APACHE III score $<25$ or $\geq 25$ ).

Patients with pulmonary infection are hypothesised to have a greater primary outcome benefit associated with continuous infusion (compared with intermittent infusion) than patients without pulmonary infection. ${ }^{8}$

The analysis for each subgroup will be performed by adding the subgroup variable, as well as its interaction with the intervention as a fixed effect to the main logistic regression model. Within each subgroup, summary measures will include raw counts and percentages within each treatment arm, as well as the OR for treatment effect with a $95 \% \mathrm{Cl}$. The results will be displayed on a forest plot including the $P$ value for heterogeneity corresponding to the interaction term between the intervention and the subgroup variable.

\section{Treatment of missing data}

If more than $3.5 \%$ of patients from the ITT population are excluded from the analysis of all-cause mortality at day 90 due to missing data, a sensitivity analysis will be performed using "worst-best" and "best-worst" case scenarios. In the "worst-best" scenario, the "worst" outcome (ie, dead at day 90) will be assigned to all 


\section{ORIGINAL ARTICLE}

\begin{tabular}{|c|c|c|}
\hline Organism & $\begin{array}{c}\text { Continuous infusion } \\
(n=\mathrm{XXXX)}\end{array}$ & $\begin{array}{c}\text { Intermittent } \\
\text { infusion } \\
(n=\mathrm{XXXX})\end{array}$ \\
\hline \multicolumn{3}{|l|}{ Gram-positive bacteria } \\
\hline $\begin{array}{l}\text { Methicillin-sensitive Staphylococcus } \\
\text { aureus }\end{array}$ & $n(\%)$ & $n(\%)$ \\
\hline $\begin{array}{l}\text { Methicillin-resistant Staphylococcus } \\
\text { aureus }\end{array}$ & $n(\%)$ & $n(\%)$ \\
\hline $\begin{array}{l}\text { Streptococcus pneumoniae (or } \\
\text { pneumococcus) }\end{array}$ & $n(\%)$ & $n(\%)$ \\
\hline $\begin{array}{l}\beta \text {-Haemolytic streptococci (group A, } \\
\text { B or C) }\end{array}$ & $n(\%)$ & $n(\%)$ \\
\hline Viridans group streptococci & $n(\%)$ & $n(\%)$ \\
\hline Enterococcus & $n(\%)$ & $n(\%)$ \\
\hline Coagulase-negative staphylococci & $n(\%)$ & $n(\%)$ \\
\hline Nocardia spp & $n(\%)$ & $n(\%)$ \\
\hline \multicolumn{3}{|l|}{ Gram-negative bacteria } \\
\hline Pseudomonas spp & $n(\%)$ & $n(\%)$ \\
\hline Burkholderia spp & $n(\%)$ & $n(\%)$ \\
\hline Haemophilus spp & $n(\%)$ & $n(\%)$ \\
\hline Acinetobacter spp & $n(\%)$ & $n(\%)$ \\
\hline Klebsiella spp & $n(\%)$ & $n(\%)$ \\
\hline Enterobacter spp & $n(\%)$ & $n(\%)$ \\
\hline Escherichia spp & $n(\%)$ & $n(\%)$ \\
\hline Serratia spp & $n(\%)$ & $n(\%)$ \\
\hline Bacteroides spp & $n(\%)$ & $n(\%)$ \\
\hline $\begin{array}{l}\text { Neisseria meningitidis (or } \\
\text { meningococcus) }\end{array}$ & $n(\%)$ & $n(\%)$ \\
\hline $\begin{array}{l}\text { Neisseria gonorrhoeae (or } \\
\text { gonococcus) }\end{array}$ & $n(\%)$ & $n(\%)$ \\
\hline Campylobacter spp & $n(\%)$ & $n(\%)$ \\
\hline Citrobacter spp & $n(\%)$ & $n(\%)$ \\
\hline Proteus spp & $n(\%)$ & $n(\%)$ \\
\hline Stenotrophomonas spp & $n(\%)$ & $n(\%)$ \\
\hline \multicolumn{3}{|l|}{ Other } \\
\hline Mycobacterium tuberculosis & $n(\%)$ & $n(\%)$ \\
\hline Mixed anaerobes & $n(\%)$ & $n(\%)$ \\
\hline Other & $n(\%)$ & $n(\%)$ \\
\hline
\end{tabular}

As there may be more than one infective organism per participant, percentages may not add up to $100 \%$. to the same conclusions, no further imputation of missing data will be performed. In case of inconsistent conclusions (ie, where one scenario leads to a statistically significant difference and not the other or where the two are significant but in different directions), we will further explore the impact of missing data by performing multiple imputations using fully conditional specification. ${ }^{9}$ The imputation model will include all-cause mortality at day 90 , the randomised treatment arm, study site and all baseline covariates (Table 3). Binary variables (eg, allcause mortality at day 90) will be imputed using an ordinal logistic regression model, categorical variables using a discriminant function method and continuous variables using linear regression. One-hundred sets of imputed data will be created and analysed using the methods described in the main analysis and adjusted analyses sections. OR estimates from the 100 imputed analyses will be combined to obtain a pooled OR and $95 \% \mathrm{Cl}$. The same 100 imputed datasets will be used for all analyses described in the "Main analysis" and "Adjusted analyses" sections.

\section{Survival analysis}

We will perform a survival analysis of time to death. The analysis will be censored at day 90 or at the time when the patient was last known to be alive, whichever occurs earlier. A Kaplan-Meier plot will be used to describe survival rates and derive median and IQR of time to death. Differences in survival will be tested using a Cox model with a random site effect using a shared-parameter frailty model. ${ }^{10}$ patients missing the outcome in one treatment group, and the "best" outcome (ie, alive at day 90) will be assigned to all patients missing the outcome in the other treatment group. The "best-worst" scenario corresponds to the reverse assignment of outcomes. If these two extreme scenarios lead

\section{Secondary efficacy outcomes}

Secondary efficacy endpoints are all binary (yes/no) variables and include:

- clinical cure at day 14 post-randomisation;

- new acquisition, colonisation or infection with a 


\section{ORIGINAL ARTICLE}

Table 7. $\beta$-Lactam antibiotic administration details

\begin{tabular}{|c|c|c|c|c|c|}
\hline \multirow[b]{2}{*}{ Administration details } & \multicolumn{2}{|c|}{$\begin{array}{l}\text { Continuous infusion } \\
(n=\mathrm{XXXX)}\end{array}$} & \multicolumn{2}{|c|}{$\begin{array}{l}\text { Intermittent infusion } \\
\quad(n=\mathrm{XXXX})\end{array}$} & \multirow[b]{2}{*}{ Significance $(P)$} \\
\hline & $\begin{array}{l}\text { Antibiotic } \\
\text { administered }\end{array}$ & $\begin{array}{l}\text { Dose prepared } \\
(\mathbf{g})^{*}\end{array}$ & $\begin{array}{c}\text { Antibiotic } \\
\text { administered }\end{array}$ & $\begin{array}{l}\text { Dose prepared } \\
(\mathbf{g})^{*}\end{array}$ & \\
\hline \multicolumn{6}{|c|}{$\beta$-Lactam antibiotic before randomisation } \\
\hline Piperacillin-tazobactam & $n(\%)$ & $\begin{array}{l}\text { Mean (SD)/ } \\
\text { median (IQR) }\end{array}$ & $n(\%)$ & $\begin{array}{l}\text { Mean (SD)/ } \\
\text { median (IQR) }\end{array}$ & \\
\hline Meropenem & $n(\%)$ & $\begin{array}{l}\text { Mean (SD)/ } \\
\text { median (IQR) }\end{array}$ & $n(\%)$ & $\begin{array}{l}\text { Mean (SD)/ } \\
\text { median (IQR) }\end{array}$ & \\
\hline \multicolumn{6}{|l|}{$\begin{array}{l}\beta \text {-Lactam antibiotic prescribed for } \\
\text { eligibility }\end{array}$} \\
\hline Piperacillin-tazobactam & $n(\%)$ & $\begin{array}{l}\text { Mean (SD)/ } \\
\text { median (IQR) }\end{array}$ & $n(\%)$ & $\begin{array}{l}\text { Mean (SD)/ } \\
\text { median (IQR) }\end{array}$ & \\
\hline Meropenem & $n(\%)$ & $\begin{array}{l}\text { Mean (SD)/ } \\
\text { median (IQR) }\end{array}$ & $n(\%)$ & $\begin{array}{l}\text { Mean (SD)/ } \\
\text { median (IQR) }\end{array}$ & \\
\hline \multicolumn{6}{|c|}{$\begin{array}{l}\text { Cumulative dose of antibiotics received } \\
(\mathrm{g})^{\dagger}\end{array}$} \\
\hline Piperacillin-tazobactam & & $\begin{array}{l}\text { Mean (SD)/ } \\
\text { median (IQR) }\end{array}$ & & $\begin{array}{l}\text { Mean (SD)/ } \\
\text { median (IQR) }\end{array}$ & $0 . X X X$ \\
\hline Meropenem & & $\begin{array}{c}\text { Mean (SD)/ } \\
\text { median (IQR) }\end{array}$ & & $\begin{array}{l}\text { Mean (SD)/ } \\
\text { median (IQR) }\end{array}$ & $0 . X X X$ \\
\hline Time on study treatment (days) $^{\ddagger}$ & & $\begin{array}{l}\text { Mean (SD)/ } \\
\text { median (IQR) }\end{array}$ & & $\begin{array}{l}\text { Mean (SD)/ } \\
\text { median (IQR) }\end{array}$ & $0 . X X X$ \\
\hline Piperacillin-tazobactam & & $\begin{array}{l}\text { Mean (SD)/ } \\
\text { median (IQR) }\end{array}$ & & $\begin{array}{c}\text { Mean (SD)/ } \\
\text { median (IQR) }\end{array}$ & \\
\hline Meropenem & & $\begin{array}{l}\text { Mean (SD)/ } \\
\text { median (IQR) }\end{array}$ & & $\begin{array}{l}\text { Mean (SD)/ } \\
\text { median (IQR) }\end{array}$ & \\
\hline
\end{tabular}

IQR = interquartile range; SD = standard deviation. * For $\beta$-lactam antibiotics before randomisation, all doses administered are reported. For the "eligibility prescription", the dose prescription at the time of randomisation is reported. For the antibiotic surveillance period (days 1-16), the 24-hour dose administered in both treatment groups is reported by antibiotic. + Cumulative dose of $\beta$-lactam antibiotic (piperacillin-tazobactam and/or meropenem) received $(\mathrm{mg})$ up to day 16 . ₹ Time on study treatment defined as the number of days between the first and last day of piperacillin-tazobactam and/or meropenem administration (up to day 16).

multiresistant organism or Clostridium difficile diarrhoea up to 14 days post-randomisation;

- all-cause ICU mortality; and

- all-cause hospital mortality.

All four outcomes will be analysed using the same approach as the analysis of 90-day mortality using a random-effects logistic regression model; however, no adjusted or subgroup analyses will be applied.

\section{Tertiary efficacy outcomes}

Tertiary efficacy outcomes include:

- ICU length of stay;

- hospital length of stay;

- duration of mechanical ventilation in ICU up to 90 days after randomisation; and

- duration of renal replacement therapy in ICU up to 90 days after randomisation.
ICU length of stay and hospital length of stay will be censored at day 90.

\section{Analysis of duration}

All four outcomes will be analysed as the number of days alive and free of the outcome (eg, days alive and free of mechanical ventilation or days alive and outside of ICU). Days requiring mechanical ventilation and renal replacement therapy are recorded for the period of ICU admission from randomisation up to day 90 , including readmissions to the ICU during this period. Days alive and free of outcome will be calculated between randomisation and day 90 with values ranging from 0 to 90 days. They will be summarised using means (SD), median (IQR), minimum and maximum and compared between treatment groups using linear regression with a fixed effect of the treatment group and a random effect of site. In addition, duration of ICU stay, 


\section{ORIGINAL ARTICLE}

\begin{tabular}{|c|c|c|c|c|}
\hline \multirow[b]{2}{*}{ Outcome } & \multicolumn{2}{|c|}{ Raw estimates } & \multicolumn{2}{|c|}{ Model estimates } \\
\hline & $\begin{array}{l}\text { Continuous } \\
\text { infusion } \\
(n=X X X X)\end{array}$ & $\begin{array}{l}\text { Intermittent } \\
\text { infusion } \\
(n=X X X X)\end{array}$ & $\begin{array}{c}\text { OR/mean } \\
\text { difference }(95 \% \\
\mathrm{Cl})\end{array}$ & $\begin{array}{l}\text { Significance } \\
\quad(P)\end{array}$ \\
\hline \multicolumn{5}{|l|}{ Primary outcome } \\
\hline $\begin{array}{l}\text { All-cause mortality at day } \\
90\end{array}$ & $n(\%)$ & $n(\%)$ & $X X . X(X X . X-X X . X)$ & $0 . X X X$ \\
\hline \multicolumn{5}{|l|}{ Secondary outcomes } \\
\hline Clinical cure at day 14 & $n(\%)$ & $n(\%)$ & $X X . X(X X . X-X X . X)$ & $0 . X X X$ \\
\hline $\begin{array}{l}\text { New acquisition, } \\
\text { colonisation or infection } \\
\text { with an MRO or } \\
\text { Clostridium difficile }\end{array}$ & $n(\%)$ & $n(\%)$ & $X X . X(X X . X-X X . X)$ & $0 . X X X$ \\
\hline All-cause ICU mortality & $n(\%)$ & $n(\%)$ & $X X . X(X X . X-X X . X)$ & $0 . X X X$ \\
\hline All-cause hospital mortality & $n(\%)$ & $n(\%)$ & $X X . X(X X . X-X X . X)$ & $0 . X X X$ \\
\hline \multicolumn{5}{|l|}{ Tertiary outcomes } \\
\hline ICU length of stay & $\begin{array}{l}\text { Mean (SD)/ } \\
\text { median (IQR) }\end{array}$ & $\begin{array}{l}\text { Mean (SD)/ } \\
\text { median (IQR) }\end{array}$ & $X X . X(X X . X-X X . X)$ & $0 . X X X$ \\
\hline Hospital length of stay & $\begin{array}{l}\text { Mean (SD)/ } \\
\text { median (IQR) }\end{array}$ & $\begin{array}{l}\text { Mean (SD)/ } \\
\text { median (IQR) }\end{array}$ & $X X . X(X X . X-X X . X)$ & $0 . X X X$ \\
\hline $\begin{array}{l}\text { Duration of mechanical } \\
\text { ventilation in ICU up to } \\
\text { day } 90\end{array}$ & $\begin{array}{l}\text { Mean (SD)/ } \\
\text { median (IQR) }\end{array}$ & $\begin{array}{l}\text { Mean (SD)/ } \\
\text { median (IQR) }\end{array}$ & $X X . X(X X . X-X X . X)$ & $0 . X X X$ \\
\hline $\begin{array}{l}\text { Duration of RRT in ICU up } \\
\text { to day } 90\end{array}$ & $\begin{array}{c}\text { Mean (SD)/ } \\
\text { median (IQR) }\end{array}$ & $\begin{array}{l}\text { Mean (SD)/ } \\
\text { median (IQR) }\end{array}$ & $X X . X(X X . X-X X . X)$ & $0 . X X X$ \\
\hline
\end{tabular}

Table 9. Summary of adverse events and protocol deviations

\begin{tabular}{|c|c|c|c|}
\hline & $\begin{array}{c}\text { Continuous infusion } \\
(n=\mathrm{XXXX)}\end{array}$ & $\begin{array}{c}\text { Intermittent infusion } \\
\quad(n=\mathrm{XXXX)}\end{array}$ & Significance $(P)$ \\
\hline Any adverse event & $n_{\mathrm{EVT}} \mathrm{n}_{\mathrm{PT}}(\%)$ & $\mathrm{n}_{\mathrm{EVT}} \mathrm{n}_{\mathrm{PT}}(\%)$ & $0 . X X X$ \\
\hline Any serious adverse event & $n_{E V T} n_{P T}(\%)$ & $\mathrm{n}_{\mathrm{EVT}} \mathrm{n}_{\mathrm{PT}}(\%)$ & $0 . X X X$ \\
\hline Resulted in death & $\mathrm{n}_{\mathrm{EVT}} \mathrm{n}_{\mathrm{PT}}(\%)$ & $\mathrm{n}_{\mathrm{EVT}} \mathrm{n}_{\mathrm{PT}}(\%)$ & \\
\hline Life-threatening & $\mathrm{n}_{\mathrm{EVT}} \mathrm{n}_{\mathrm{PT}}(\%)$ & $\mathrm{n}_{\mathrm{EVT}} \mathrm{n}_{\mathrm{PT}}(\%)$ & \\
\hline $\begin{array}{l}\text { Required new or prolonged } \\
\text { hospitalisation }\end{array}$ & $\mathrm{n}_{\mathrm{EVT}} \mathrm{n}_{\mathrm{PT}}(\%)$ & $\mathrm{n}_{\mathrm{EVT}} \mathrm{n}_{\mathrm{PT}}(\%)$ & \\
\hline $\begin{array}{l}\text { Resulted in persistent or } \\
\text { significant disability }\end{array}$ & $\mathrm{n}_{\mathrm{EVT}} \mathrm{n}_{\mathrm{PT}}(\%)$ & $n_{E V T} n_{P T}(\%)$ & \\
\hline $\begin{array}{l}\text { Was a congenital anomaly or } \\
\text { birth defect }\end{array}$ & $\mathrm{n}_{\mathrm{EVT}} \mathrm{n}_{\mathrm{PT}}(\%)$ & $\mathrm{n}_{\mathrm{EVT}} \mathrm{n}_{\mathrm{PT}}(\%)$ & \\
\hline Any SUSAR & $n_{E V T} n_{P T}(\%)$ & $n_{E V T} n_{P T}(\%)$ & $0 . X X X$ \\
\hline Any protocol deviation & $n_{E V T} n_{P T}(\%)$ & $n_{E V T} n_{P T}(\%)$ & $0 . X X X$ \\
\hline $\begin{array}{l}\text { Randomisation of ineligible } \\
\text { patient }\end{array}$ & $\mathrm{n}_{\mathrm{EVT}} \mathrm{n}_{\mathrm{PT}}(\%)$ & $n_{E V T} n_{P T}(\%)$ & \\
\hline $\begin{array}{l}\text { Follow-up assessment not } \\
\text { done correctly }\end{array}$ & $\mathrm{n}_{\mathrm{EVT}} \mathrm{n}_{\mathrm{PT}}(\%)$ & $\mathrm{n}_{\mathrm{EVT}} \mathrm{n}_{\mathrm{PT}}(\%)$ & \\
\hline Other & $n_{E V T} n_{P T}(\%)$ & $n_{E V T} n_{P T}(\%)$ & \\
\hline
\end{tabular}

$\mathrm{n}_{\mathrm{EVT}}=$ total number of events; $\mathrm{n}_{\mathrm{PT}}=$ number of patients experiencing at least one event; SUSAR = suspected unexpected serious adverse reaction. hospital stay, mechanical ventilation and renal replacement therapy will be reported for all participants and separately for survivors and nonsurvivors, but no formal tests will be applied.

\section{Analysis of time to discharge}

Time to discharge alive from index ICU admission and time to discharge alive from index hospital admission will be summarised using cumulative incidence functions treating mortality as a competing risk. Medians and IQRs of time to discharge will be obtained from the cumulative incidence functions. The effect of the intervention will be estimated as the hazard ratio and its $95 \% \mathrm{Cl}$ obtained from a Cox model of the causespecific hazard, which estimates the risk of discharge in subjects who are still alive and have not yet been discharged. ${ }^{11}$ To model potential withinsite correlations due to stratification, we will use a shared-parameter frailty Cox model with a fixed effect of treatment and a random site effect. ${ }^{10}$ The proportional hazard assumption will be assessed by visually inspecting a plot of $\log (-\log ($ survival)) versus log(time).

\section{Safety outcomes}

Adverse events, serious adverse events and 


\begin{tabular}{|c|c|c|c|}
\hline \multicolumn{4}{|c|}{ Table 10. Cause and place of death } \\
\hline Cause*/place of death & $\begin{array}{l}\text { Continuous } \\
\text { infusion } \\
(n=X X X X)\end{array}$ & $\begin{array}{l}\text { Intermittent } \\
\text { infusion } \\
(n=X X X X)\end{array}$ & $\begin{array}{c}\text { Significance } \\
(P)\end{array}$ \\
\hline Place of death & & & $0 . X X X$ \\
\hline ICU & $n(\%)$ & $n(\%)$ & \\
\hline Ward & $n(\%)$ & $n(\%)$ & \\
\hline Home & $n(\%)$ & $n(\%)$ & \\
\hline Other & $n(\%)$ & $n(\%)$ & \\
\hline Proximate cause of death & & & $0 . X X X$ \\
\hline Cause 1 & $n(\%)$ & $n(\%)$ & \\
\hline Cause 2 & $n(\%)$ & $n(\%)$ & \\
\hline ... & $n(\%)$ & $n(\%)$ & \\
\hline Cause k & $n(\%)$ & $n(\%)$ & \\
\hline \multicolumn{4}{|l|}{ Underlying cause of death } \\
\hline Cause 1 & $n(\%)$ & $n(\%)$ & \\
\hline Cause 2 & $n(\%)$ & $n(\%)$ & \\
\hline$\ldots$ & $n(\%)$ & $n(\%)$ & \\
\hline Cause k & $n(\%)$ & $n(\%)$ & \\
\hline
\end{tabular}

\section{Table 11. Proposed figures}

\section{Figure 1. CONSORT flow diagram}

\section{Figure 2. Bar chart of daily subject disposition}

Bar chart showing, for each day between day 1 and day 90, the proportion of patients in each arm who fall into one of the following five categories:

- alive and in ICU;

- discharged from ICU but still in hospital;

- discharged from hospital;

- dead; and

- with unknown status

The figure will consist of two (one plot per arm) stacked bar charts with one bar per day and, within each bar, the proportion of patients in each category (summing to 100\%)

Figure 3. Longitudinal mean plot of the daily dose of antibiotics

The figure will report mean daily dose by treatment arm with $95 \% \mathrm{Cl}$ for days $1-16$. Raw means will be displayed on the graph as numbers near each dot and denominators will be included below the $\mathrm{x}$-axis

\section{Figure 4. Cumulative incidence function of time to death}

The figure will show the number at risk every 10 days, display median and IQRs, as well as results from the Cox model (hazard ratio, $95 \% \mathrm{Cl}$ and $P$ value)

Figure 5. Cumulative incidence function of time to alive discharge from index ICU admission The figure will show the number at risk every 10 days, display median and IQRs as well as results from the Cox model (hazard ratio, 95\% Cl and $P$ value).

Figure 6. Cumulative incidence function of time to alive discharge from index hospital admission

The figure will show the number at risk every 10 days, display median and IQRs as well as results from the Cox model (hazard ratio, 95\% Cl and $P$ value).

\section{Figure 7. Forest plot for subgroup analysis of mortality at day 90}

CONSORT = Consolidated Standards of Reporting Trials; ICU = intensive care unit; IQR = interquartile range. suspected unexpected serious adverse reactions will be summarised as the number and proportion of patients experiencing at least one event using a per protocol analysis. The total number of events will be reported and tabulated by category of event. Proportions of patients with adverse events will be compared between treatment arms using Fisher exact test, both overall and by body system (Table 9). A listing of all adverse drug reactions will be reported. Causes (proximate and underlying) and places of death (by day 90) will be categorised and the distribution compared between the two treatment arms using Fisher exact test (Table 10).

\section{Proposed figures}

The proposed figures are summarised in Table 11.

\section{Future analyses}

It is intended that there will be additional exploratory and region-specific health economic analyses that are conducted and reported separately to the main results of the study. These additional analyses include, but are not limited to, a planned nested cohort health economic analysis, a pharmacokineticpharmacodynamic substudy evaluation, and exploratory analyses based on geographic, clinical and mechanistic factors of interest, such as compliance with randomised treatment, type of pathogenic organism, site of infection and country or region.

\section{Current status}

The study commenced recruitment in March 2018 and reached the study mid-point (3500th patient recruited) in 
Figure 2. Detectable difference (D1) by baseline mortality in the control group (P2) for various sample sizes $(N)$ with $80 \%$ power

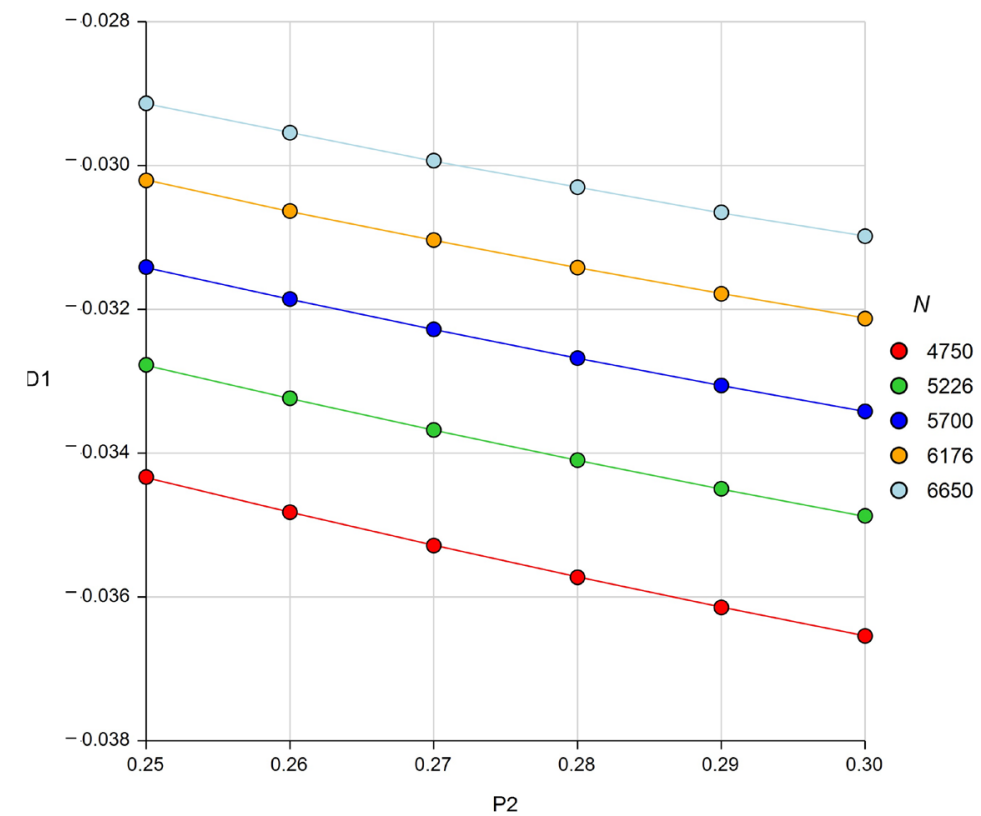

Sample sizes refer to $5000,5500,6000,6500$ and 7000 respectively, after adjusting for $5 \%$ loss to follow-up.
April 2020. Recruitment was estimated to be completed by June 2021; however, final recruitment projections are dependent on the impact of the coronavirus disease 2019 (COVID-19) pandemic, with 5400 participants recruited as of July 2021.

\section{COVID-19 pandemic contingency}

Due to the significant impact on study recruitment from the COVID-19 pandemic and uncertain future impact on recruitment, revised power and effect size calculations have been performed as a pandemic contingency measure. Assuming $5 \%$ of patients lost to follow-up, the detectable difference for stopping the trial at $5000,5500,6000,6500$ and 7000 participants at various baseline mortality rates are detailed in Figure 2 and Figure 3 for $80 \%$ and 90\% power respectively, with $\alpha=0.05$. While the intent is to reach a sample size of 7000 , the BLING III management committee will continue to monitor the situation and, if required, make an earlier stopping decision on the basis of estimated achievable recruitment and power considerations.

\section{Conclusion}

Figure 3. Detectable difference (D1) by baseline mortality in the control group (P2) for various sample sizes ( $N$ ) with $\mathbf{9 0 \%}$ power

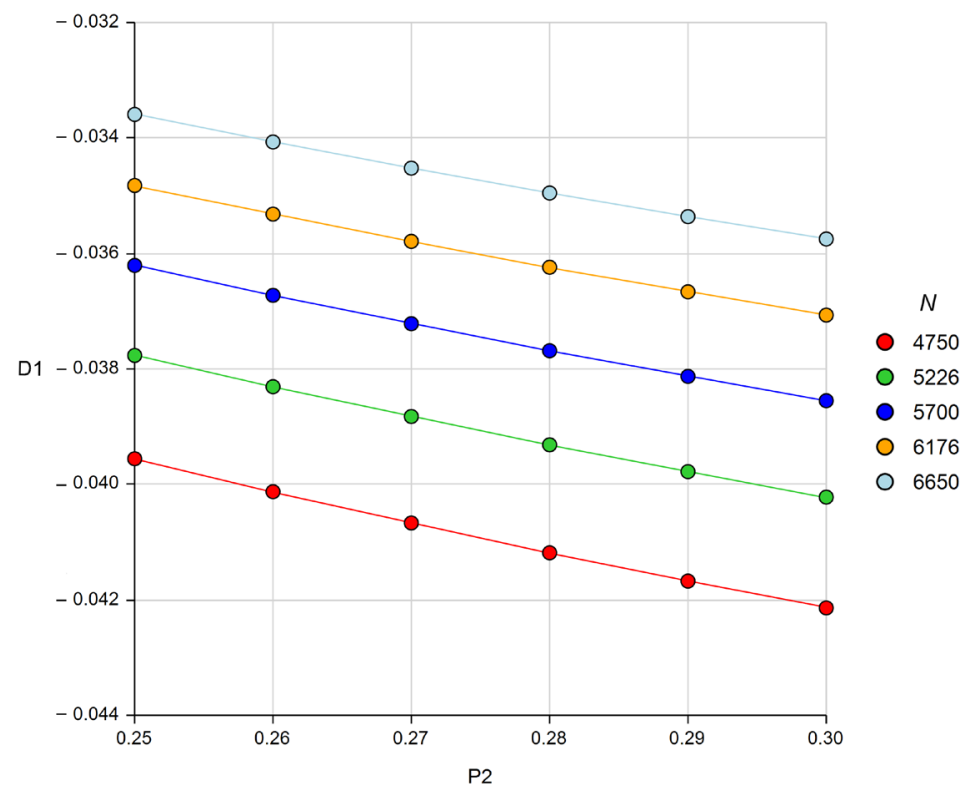

Sample sizes refer to 5000,5500, 6000, 6500 and 7000 respectively, after adjusting for $5 \%$ loss to follow-up.
The BLING III study will provide robust and reliable evidence of whether administration of piperacillin-tazobactam or meropenem by continuous infusion will result in improved outcomes for critically ill patients with sepsis compared with intermittent infusion. This statistical analysis plan is published before unblinding and completion of data collection to minimise analysis bias and facilitate public access and transparent analysis and reporting of study results.

Acknowledgements: The study is endorsed by the Australian and New Zealand Intensive Care Society Clinical Trials Group, the Australasian Society for Infectious Diseases Clinical Research Network and the European Society of Clinical Microbiology and and supported by the Infection Section of the European Society of Intensive Care Medicine. The study is funded by the National Health and Medical Research Council (Australia), the Belgian Health Care Knowledge Centre (KCE), the Health Research Infectious Diseases. The study has been reviewed 


\section{ORIGINAL ARTICLE}

Council of New Zealand and the National Institute for Health Research (United Kingdom) with additional funding sourced in other regions. Funding bodies have no input into the design, management or reporting of the trial.

\section{Competing interests}

Jeffrey Lipman has served as a board member for the Bayer ESICM and MSD Antibacterials Advisory Boards and given lectures with honoraria from Pfizer and MSD. Stephen Brett has received a speaker's fee and attended an Advisory Board from Orion Pharma. Jan De Waele has attended Advisory Boards, acted as a consultant to, or given lectures with honoraria from Accelerate, Bayer Healthcare, Grifols, MSD and Pfizer. David Paterson has received research grants from AstraZeneca and has attended Advisory Boards, acted as a consultant to, or given lectures with honoraria from Three Rivers Pharmaceuticals, Merck, AstraZeneca, SanofiAventis, Pfizer, Johnson and Johnson, Shionogi, Sumitomo and Leo Pharmaceuticals. Jason Roberts has served as a consultant for MSD, Bayer, Astellas, bioMerieux and Accelerate Diagnostics and has received research grants from MSD, The Medicines Company, Pfizer, Astellas and Cardeas Pharma. Claire Roger has received speaker's fees from Pfizer and MSD. Colman Taylor owns a company, Health Technology Analysts, which provides consulting services to pharmaceutical companies, medical device companies and the Australian Government.

\section{Author details \\ Laurent Billot ${ }^{1,2}$ \\ Jeffrey Lipman ${ }^{3,4,5}$ \\ Stephen J Brett ${ }^{5,6,7}$ \\ Jan J De Waele ${ }^{8}$ \\ Menino Osbert Cotta ${ }^{3,4}$ \\ Joshua S Davis 9,10 \\ Simon Finfer $1,11,12$ \\ Naomi E Hammond 1,2,11 \\ Serena Knowles ${ }^{1}$ \\ Shay McGuinness ${ }^{13}$ \\ John Myburgh ${ }^{1,2}$ \\ David L Paterson ${ }^{3,4}$ \\ Sandra Peake $14,15,16$ \\ Dorrilyn Rajbhandari ${ }^{1}$ \\ Andrew Rhodes ${ }^{17,18}$ \\ Jason A Roberts $3,4,5$ \\ Claire Roger ${ }^{5}$ \\ Charudatt Shirwadkar ${ }^{19}$ \\ Therese Starr ${ }^{3}$ \\ Colman Taylor ${ }^{1,2}$ \\ Joel M Dulhunty 3,4,20 \\ For the BLING III Investigators}

1 George Institute for Global Health, Sydney, NSW, Australia.

2 Faculty of Medicine, University of New South Wales, Sydney, NSW, Australia.

3 Royal Brisbane and Women's Hospital, Brisbane, QLD, Australia.

4 University of Queensland, Brisbane, QLD, Australia.
5 Department of Anaesthesiology, Critical Care and Emergency Medicine, CHU Nîmes, University Montpellier, Nîmes, France.

6 Imperial College Healthcare NHS Trust, London, United Kingdom.

7 Department of Surgery and Cancer, Imperial College London, London, United Kingdom.

8 Department of Critical Care Medicine, Ghent University Hospital, Ghent, Belgium.

9 Global and Tropical Health Division, Menzies School of Health Research, Darwin, NT, Australia.

10 Department of Infectious Diseases, John Hunter Hospital, Newcastle, NSW, Australia.

11 Malcolm Fisher Department of Intensive Care, Royal North Shore Hospital, St Leonards, NSW, Australia.

12 School of Public Health, Imperial College London, London, United Kingdom.

13 Auckland City Hospital, Auckland, New Zealand.

14 Queen Elizabeth Hospital, Adelaide, SA, Australia.

15 School of Medicine, University of Adelaide, Adelaide, SA, Australia.

16 School of Epidemiology and Preventive Medicine, Monash University, Melbourne, VIC, Australia.

17 St George's University Hospitals NHS Foundation Trust, London, United Kingdom.

18 St George's University of London, London, United Kingdom.

19 Blacktown Hospital, Sydney, NSW, Australia.

20 Redcliffe Hospital, Brisbane, QLD, Australia.

Correspondence: Ibillot@georgeinstitute.org

doi: https://doi.org/10.51893/2021.3.OA4

\section{References}

1 Lipman J, Brett SJ, De Waele JJ, et al. A protocol for a phase 3 multicentre randomised controlled trial of continuous versus intermittent $\beta$-lactam antibiotic infusion in critically ill patients with sepsis: BLING III. Crit Care Resusc 2019; 21: 63-8.

2 Dulhunty JM, Roberts JA, Davis JS, et al. A multicenter randomized trial of continuous versus intermittent $\beta$-lactam infusion in severe sepsis. Am J Respir Crit Care Med 2015; 192: 1298-305.

3 Holm S. A simple sequentially rejective multiple test procedure. Scand J Stat 1979; 6: 65-70.

4 Schulz KF, Altman DG, Moher D, CONSORT Group. CONSORT 2010 statement: updated guidelines for reporting parallel group randomised trials. BMJ 2010; 340: c332.

5 Kahan BC, Morris TP. Improper analysis of trials randomised using stratified blocks or minimisation. Stat Med 2012; 31: 328-40.

6 Kahan BC. Accounting for centre-effects in multicentre trials with a binary outcome - when, why, and how? BMC Med Res Methodol 2014; 14: 20. 


\section{ORIGINAL ARTICLE}

7 Reeve R. Confidence interval of difference of proportions in logistic regression in presence of covariates. Stat Methods Med Res 2018; 27: 451-65.

8 Taccone FS, Laupland KB, Montravers P. Continuous infusion of $\beta$-lactam antibiotics for all critically ill patients? Intensive Care Med 2016; 42: 1604-6.

9 van Buuren S. Multiple imputation of discrete and continuous data by fully conditional specification. Stat Methods Med Res 2007; 16: 219-42.

10 Ripatti S, Palmgren J. Estimation of multivariate frailty models using penalized partial likelihood. Biometrics 2000; 56: 1016-22.

11 Austin PC, Lee DS, Fine JP. Introduction to the analysis of survival data in the presence of competing risks. Circulation 2016; 133: 601-9. 